\title{
EM DEBATE
}

\section{ESCREVER E EDITAR: COMPROMISSO COM A DISSEMINAÇÃO DE CONHECIMENTO}

\author{
Maria do Carmo Guedes \\ Pontifícia Universidade Católica de São Paulo - PUCSP
}

\begin{abstract}
Drovocada a participar do debate sobre avaliação de periódicos, começo - com algumas considerações sobre o próprio avaliar; continuo, recuperando do processo de comunicação científica o papel e a importância dos periódicos; e completo, lembrando que o que será depende do que fizermos hoje.
\end{abstract}

\section{Avaliando avaliações}

Desde o início de seus trabalhos, as Comissões de Avaliação ANPEPP/CAPES vêm se dispondo a explicar o trabalho realizado na avaliação dos periódicos em Psicologia. Em quase todos os encontros científicos gerais e em boa parte dos setoriais, há sempre uma atividade que reúne interessados (editores científicos, mas não só) e dois ou mais membros da Comissão.

1 Professora do Programa de Pós-Graduação em Psicologia Social e coordenadora do Núcleo de Estudos em História da Psicologia. Endereço eletrônico: mcguedes@pucsp.br 
Infelizmente, as discussões se reduzem, nesses momentos, a questões pontuais, discordâncias específicas sobre o instrumento, sua aplicação e interpretação. O que se tem, então, são explicações de como e porque se fez o que foi feito. Mesmo quando se assume que poderia ter sido feito de outro modo, o que ocorre é que cada ponto é parte de um conjunto maior, que dirige (como, aliás, deve ser) as decisões pontuais. Assim, apesar de poder concordar com este outro modo, um representante da Comissão não pode prometer mudanças sem confrontá-las com o projeto maior.

Entendo, desse modo, porque "as reflexões presentes no debate sobre a questão da endogenia, efetuado no IX Encontro Nacional da $\operatorname{ABEC}^{2}$ (...) não tiveram repercussão nos parâmetros norteadores da última avaliação, que continuaram os mesmos em relação à anterior, embora estivessem presentes no evento membros da Comissão de Avaliação" (Loffredo, Bicalho, Fernandes \& Bergamasco, 2003, p. 201). Decerto, porque os parâmetros deviam ser outros.

Na Educação, não é pouca a literatura que - a propósito de avaliação trata das dificuldades enfrentadas pela área. Sobre avaliação institucional, por exemplo, há hoje uma referência obrigatória: a RAIES - Rede de Avaliação Institucional da Educação Superior. ${ }^{3}$

A ela recorro para a análise que me proponho, ao aceitar o debate aberto pelo texto "Comentários sobre as avaliações realizadas pelas comissões CAPES/ANPEPP para avaliação de periódicos da área de Psicologia”.

2 ABEC - Associação Brasileira de Editores Científicos. As autoras se referem a evento acontecido em novembro de 2003, em Caxambu. Cabe lembrar: com sua história de quase 20 anos, foi a primeira vez que a ABEC recebeu um grande número de editores de Ciências Humanas, "ameaçando" a hegemonia das ciências ditas duras. Mas esta ameaça foi logo resolvida pela organização: para as discussões, os representantes das Humanas deveriam optar por um de três grupos: o das revistas interdisciplinares, o da Psicologia ou o da Educação (as duas subáreas mais representadas no evento). Enquanto isso, os representantes das áreas duras podiam entrar em qualquer dos outros grupos formados por temas em edição ou editoração científicas.

3 A RAIES publica, desde 1999, uma revista quadrimestral - Avaliação, e já editou diversas coletâneas com artigos sobre o tema. 
Por desnecessário, tão claramente e tão bem fundamentados os argumentos apresentados, não o discuto diretamente. Também, porque já bem contada (desde a decisão da proposta, publicada em 1999 em Infocapes, vol. 7, n. 3, Yamamoto et al., pp. 7-13), não preciso tratar da história deste avaliar, desde que a CAPES decidiu que era preciso ter um ranking das revistas científicas, para aperfeiçoar seus instrumentos de avaliação da pósgraduação e a ANPEPP decidiu colaborar nisso. Apenas teço considerações sobre avaliar periódicos em psicologia na nossa realidade, a partir de um suposto, a meu ver, básico: o do caráter ideológico de qualquer atividade, se há mais de um modo de realizá-la.

Não é de hoje a preocupação no Brasil com avaliação do ensino superior. Diz-se mesmo que temos agora uma cultura de avaliação que começa a ser exportada. Parece, no entanto, não haver ainda, talvez porque campo de muitos interesses, suficiente atenção a conhecimentos e experiências construídos na área. Dias Sobrinho (2004) chega a afirmar, no Editorial do trigésimo número de Avaliação, que o que se consolidou no país é "a cultura de controle, medição e ranking, não de avaliação".

Afinal, o que sabemos sobre avaliação que não seja instrumento de intimidação e disciplinarização? Sobre as consequiências de determinadas abordagens avaliativas? De avaliação não como ponto culminante de um projeto, mas parte dele? Como trabalhar com uma ética voltada ao convívio social? É preciso que lidemos sempre com dicotomias: ética x técnica, quantidade $\mathrm{x}$ qualidade, parte $\mathrm{x}$ todo, performance $\mathrm{x}$ sentido, participação $\mathrm{x}$ assujeitamento, ação $\mathrm{x}$ transformação? O que é preciso partilhar, como suposto indispensável, para não correr o risco de sairmos em debate sem chance de nos encontrarmos?

Posso estar enganada, mas penso que talvez baste assumirmos avaliação como um processo, por isso, contínuo. Por isso, também, com objetivos constantemente revistos, parte da permanente postura de autocrítica indispensável ao pesquisador e à instituição universitária. No caso dos periódicos - "responsáveis pela disseminação ágil e eficiente da informação científica" 
(Biojone, 2003) -, objetivos que levam a avaliar o trabalho de um pesquisador professor em "novos" papéis - de autores, de pareceristas, de editores.

\section{Escrita e leitura: faces da mesma moeda}

Escrito, um artigo ou ensaio depende de um periódico científico, impresso ou eletrônico, por sua dupla função de "depósito legal" do texto como documento e de compromisso com sua circulação.

Entretanto, para além do registro de conhecimento produzido e sua circulação, o periódico é também o espaço que materializa o artigo, que o torna objeto de leitura; já a circulação é indispensável, não apenas para livrar o editor dos exemplares impressos ou fechar o trabalho do editor de revista eletrônica: a circulação é que assegura à escrita sua "reatualização" (Babo, 1993) - a leitura.

Vale dizer, sem a leitura, nem autor nem editor científico terão completado seus trabalhos de escrever e editar.

Estudos sobre citação constituem hoje um campo bastante avançado, mesmo no Brasil - basta passar os olhos pelos Sumários de apenas um periódico da área, o Ciência da Informação (do IBICT - Instituto Brasileiro de Informação em Ciência e Tecnologia, ISSN 0100-1965). Loffredo et al. (2003) recorreram também a este tipo de análise, citando Trzesniak (2001), para quem um índice de qualidade de um periódico é dado pelo "mercado", isto é, pela "quantidade de vezes em que é citado e o acesso às citações".

Uma primeira questão, a meu ver, é que esta forma de quantificar trabalha apenas com uma das unidades que deveriam ser consideradas, pois o que é citado não é exatamente a revista, mas um artigo, de certo assunto, de um ou mais autores, que pode ser encontrado em determinada revista.

Deixo, entretanto, aos pesquisadores da ciência da informação a preocupação em aprimorar seus instrumentos, se a isso se prepuserem. Ainda que entenda porque as autoras a realizaram, prefiro análise com categorias 
mais amplas, como "impacto do periódico na área", mesmo que me falte aprender como fazê-la. De todo modo, quero levantar aqui a questão: sabemos que o artigo foi citado e possivelmente lido. Mas, e a Revista?

Entrevistando pós-graduandos ${ }^{5}$ de quatro universidades, recémmestres com título obtido em Educação ou Psicologia, descobrimos que a grande maioria dos artigos referidos em suas dissertações haviam sido localizados a partir de indicação do orientador, de outro professor ou de um colega; para os pouco mais de $20 \%$ restantes, a partir de outros artigos. Pouquíssimos costumam consultar revistas, a menos que diretamente indicadas. Pior ainda: em mais de $50 \%$ dos casos, o artigo tinha sido lido em fotocópia.

Não é à toa que um dos pontos levantados em quase todas as reuniões de editores científicos é o da dificuldade da distribuição de seus periódicos. ${ }^{6}$ E a fotocópia tem culpa nisso, mas, talvez, não toda. Esta é uma das questões de que temos precisado fugir. Para um professor é tão importante que o aluno leia, que muitos fecham os olhos às condições de que ele se vale para isso.

Quanto ao parecerista, seu compromisso vem da necessidade de pesquisadores mais experientes verificarem a correção de um artigo ou ensaio, além de sua real contribuição ao conhecimento na área. O problema é que muitas vezes se esquece que este serviço tem por nome "avaliação por pares”. Isto é, não podem ser, como diz Cecília Meireles em Cancioneiro da Inconfidência: “... tão bons vassalos, que esqueceram os amigos” (os pares, eu diria). É por isso que um parecer tem que ser bem consubstanciado. Não apenas para facilitar o trabalho do Editor, mas para que o Autor possa aprender do pesquisador mais experiente.

4 Bem que a CAPES tentou, mas não soubemos à época comprar essa briga...

5 Levantamento realizado em 2003/2004, como parte de pesquisa sobre leitor e leitura em Educação, para o Comped/INEP (Comitê de Produtores da Informação em Educação/ Instituto Nacional de Estudos Pedagógicos).

6 É muito fácil hoje defender o periódico eletrônico como forma de resolver problemas de distribuição. Ver Biojone (2003). 


\section{Concluindo}

Quero crer, partilhamos todos a esperança de que a ANPEPP volte a assumir sua própria tarefa: a de pensar e, porque processo, repensar continuamente, "os princípios que devem nortear a construção e aprimoramento dos instrumentos para a avaliação dos periódicos da área" (Loffredo et al., 2003). Não estará deixando, com isso, de colaborar com a CAPES.

Mas há ainda a questão: é só isso que compete à ANPEPP? Construir e aprimorar instrumentos?

Em 2004, o Simpósio de Pesquisa e Intercâmbio Científico da ANPEPP inovou, ao instalar os Fóruns de Discussão. Não só: mostrou a que vinham, pois em relação ao assunto deste debate, propôs um fórum intitulado "Produção e Publicação em Psicologia". Infelizmente, como se pôde ouvir do Relatório ao final do Simpósio, mais uma vez prevaleceu a discussão de pontos específicos de um instrumento que, afinal, nem se sabe se está sendo "aprimorado". Sobre publicação, só periódicos foram contemplados, quando a própria CAPES fala, há quase dois anos, em avaliar livros. ${ }^{7}$ E nada sobre produção, menos ainda sobre a relação prometida no título do fórum.

No entanto, a ANPEPP já fez muito por isso. À moda de exemplo, lembro que pelo menos em duas gestões o Conselho de Representantes teve oportunidade de discutir o assunto produção-publicação. De uma delas, resultou a criação de um Grupo de Trabalho que chegou a publicar uma coletânea com os excelentes trabalhos apresentados no Simpósio. A outra ensaiou uma publicação que se propunha periódica - as Coletâneas ANPEPP que (infelizmente) não vingou, apesar do "sucesso" da idéia no momento. Ainda assim, esse projeto representa a produção da pós-graduação brasileira

7 Cabe registrar que, antecipando-se à ANPEPP, editores comerciais estão já disaltindo modos de influir nessa avaliação. E que, na Psicologia (embora nem só), o compromisso com ensino vem respondendo por um tipo particular de livro - a coletânea -, algo mais ágil e de melhor distribuição que os periódicos. Cabe lembrar ainda que atendiam à interdisciplinaridade, quando o CNPq ainda só apoiava periódicos por área. 
em Psicologia num determinado momento ${ }^{8}$, documento precioso para historiadores da área no país.

A pergunta hoje é: e daí? O que vai acontecer? Penso que depende do que fizermos agora.

O artigo de Loffredo et al. (2003), para além do que pretendeu (p. 222), provocou em mim, desmotivada que estava, a vontade de voltar ao debate. Entretanto, acrescentando a ele a procura dos objetivos que se perderam no tempo, sabendo também que deve haver outros ainda por criar.

Acho mesmo que se nosso tema se restringir a melhorar o instrume nto, atendendo ao ranking necessário à CAPES ou para facilitar a distribuição das parcas verbas destinadas à área, não há muito o que discutir. Mesmo porquê, especialistas em medição sabem fazer isso muito bem (e a CAPES tem ótimos técnicos na área). ${ }^{9}$ E sempre haverá um novo corte para assegurar que devemos melhorar nossas revistas, mas...

Então, vamos assumir o desafio maior? Vamos ousar, ou apenas repetir o que já se fez (ainda que melhorando)?

\section{Referências}

Babo, M. A. (1993). A escrita do livro (Col. Passagens). Lisboa: Vega.

Biojone, M. R. (2003). Os periódicos científicos na comunicação da ciência. São Paulo: EDUC / FAPESP.

8 Sabemos bem das diversas críticas que o conjunto mereceu, em especial a de que nem todos os tomos usaram avaliação por pares na decisão do que publicar. Mas não teria sido o caso de estabelecer normas em relação a isso, em vez de apenas desistir?

9 Em 1984, o CNPq apoiava 23 periódicos, sendo 4 de "Ciências Sociais Aplicadas e Humanas", e, destes, um em Psicologia. Vinte anos depois, quanto se avançou? E se foi pouco, nem é de estranhar, já que as Ciências Humanas só entraram no conjunto de áreas da Academia Brasileira de Ciências em 1999. 
Dias Sobrinho, J. (2004). Editorial. Avaliação: Revista da Rede de Avaliação da Educação Superior, (30).

Loffredo, A. M., Bicalho, H. M, Fernandes, M. I., \& Bergamasco, N. H. P. (2003). Comentários sobre as avaliações realizadas pelas Comissões CAPES/ANPEPP para avaliação dos periódicos da área de Psicologia. Psicologia USP, 14( 3), 201-272.

Yamamoto, O. H., Koller, S. H., Guedes, M. C., LoBianco, A. C., Sá, C. P., Hutz, C. S. et al. (1999). Periódicos científicos em psicologia: uma proposta de avaliação. Infocapes, 7(3), 7-13.

Recebido em 10.05.2005 Aceito em 13.05.2005 